\title{
Domesticated dogs (Canis familiaris) react to what others can and cannot hear
}

\author{
Shannon M.A. Kundey ${ }^{\mathrm{a}, *}$, Andres De Los Reyes ${ }^{\mathrm{b}}$, Chelsea Taglang ${ }^{\mathrm{a}}$, \\ Rebecca Allen ${ }^{\mathrm{a}}$, Sabrina Molina ${ }^{\mathrm{a}}$, Erica Royer ${ }^{\mathrm{a}}$, Rebecca German ${ }^{\mathrm{a}}$ \\ a Department of Psychology, Hood College, Frederick, MD 21701, USA \\ b Department of Psychology, University of Maryland at College Park, 20742, USA
}

\section{A R T I C L E I N F O}

\section{Article history:}

Accepted 3 June 2010

Available online 3 July 2010

\section{Keywords:}

Canis familiaris

Dog

Perspective taking

Social cognition

\begin{abstract}
A B S T R A C T
Recent research suggests some nonhuman primates (e.g., chimpanzees, rhesus macaques) consider what others hear when acting in competitive situations. We explored whether dogs living in private homes or sourced from an animal shelter would show this same predilection. Following an inhibition task where dogs (Canis familiaris) were commanded not to take a treat left on a plate by a human, we presented subjects with the opportunity to take food from one of two containers. These containers were located within the proximity of a human gatekeeper who was either looking straight ahead or not looking at the time of choice. One container was silent when food was inserted or removed while the other was noisy. Among pet dogs (20 total; 10 in each condition) randomly assigned to the Looking or Not Looking condition, four subjects approached the silent container in the Looking condition (binomial test: $P=0.8$ ) while 10 approached the silent container in the Not Looking condition (binomial test: $P=0.004$ ). We compared pet dogs' pattern of performance between conditions using a chi-square test for independence, which indicated that dogs significantly preferred the silent container only in the Not Looking condition $\left(\chi_{1}^{2}=8.8, P=0.003\right)$. This outcome suggests dogs preferentially attempted to retrieve food silently only when silence was germane to obtaining food unobserved by the human gatekeeper. Interestingly, dogs sourced from a local animal shelter evidenced similar outcomes. Among shelter dogs (20 total; 10 in each condition) randomly assigned to the Looking or Not Looking condition, four subjects approached the silent container in the Looking condition (binomial test: $P=0.8$ ) while nine approached the silent container in the Not Looking condition (binomial test: $P=0.02$ ). We compared shelter dogs' pattern of performance between conditions using a chi-square test for independence, which indicated that dogs significantly preferred the silent container only in the Not Looking condition $\left(\chi_{1}^{2}=5.5, P=0.02\right)$. This result suggests shelter dogs, like pet dogs, preferentially tried to retrieve food silently only if silence was relevant to obtaining food unobserved by a human gatekeeper. This result conflicts with other recent data suggesting that shelter dogs perform more poorly than pet dogs in tasks involving human social cues.
\end{abstract}

(c) 2010 Elsevier B.V. All rights reserved.

\footnotetext{
* Corresponding author at: Hood College, Department of Psychology, 401 Rosemont Avenue, Room ROS 27, Frederick, MD 21701,

USA. Tel.: +1 3016963877 .

E-mail address: kundey@hood.edu (S.M.A. Kundey).
}

\section{Introduction}

Researchers curious about the cognitive capacities of nonhuman animals typically have studied nonhuman primates (hereafter, primates). Due to our shared ancestry, primates have been considered by many the likeliest 
contenders to display basic forms of human cognitive skills. However, recent research with domestic dogs (Canis familiaris) suggests dogs' skills in social cognitive tasks frequently appear more flexible and similar to those of humans than species more closely (e.g., Horowitz, 2009) or distantly (e.g., Schloegl et al., 2008) related to humans phylogenetically. Some have posited that this may be due to dogs' close association with humans through domestication (e.g., Vilà et al., 1997; Clutton-Brock, 1999). Indeed, many investigations highlight dogs' acute sensitivity to humans' social and communicative cues (e.g., Agnetta et al., 2000; Hare and Tomasello, 2005; Lakatos et al., 2009).

Numerous studies note dogs' proficient use of humans' attentional state, as evidenced by their ability to modify their behaviour to accord with where humans are visually attending (e.g., Call et al., 2003; Schwab and Huber, 2006). For example, Call et al. (2003) presented dogs with trials in which a human forbid them to eat a piece of food. During some trials, the human maintained visual contact with the dog. In others, the human left the room, turned her back, engaged in a distracting activity, or closed her eyes. When the human visually attended to the dogs, they were less likely to retrieve food and approached the food in an indirect manner, suggesting dogs were sensitive to the human's attentional state.

While the issue of animals' sensitivities to human attentional states has not been explored at length within the canine literature, we can look to work with other species. For example, a variety of primates have shown skill in determining what a conspecific can see as they compete for a limited amount of food (e.g., Flombaum and Santos, 2005; Hare et al., 2006; Bräuer et al., 2007; but see e.g., Karin-d'Arcy and Povinelli, 2002; Hare et al., 2003). For example, Hare et al. (2006) provided evidence that some chimpanzees spontaneously chose to approach food items via a route hidden from a human competitor's view rather than a route from which they could be observed. Rhesus macaques also chose to take food from humans who could not see them in conditions where the humans' eyes were facing away or when the human's face was blocked by an opaque barrier (Flombaum and Santos, 2005). Similar results have been demonstrated with domestic goats (Capra hircus) using a competition paradigm (Kaminski et al., 2005). Ravens (Corvus corax) have also been shown to adjust their caching and foraging behaviour in the presence of conspecific competitors (e.g., Bugnyar and Heinrich, 2006; Bugnyar and Kotrschal, 2004).

The evaluation of what competitors know does not appear limited to information gleaned from the visual domain (Santos et al., 2006). Santos et al. presented rhesus macaques with the opportunity to take food from a human competitor who did or did not have visual access to baited containers. One container was noisy when manipulated while the other was not. Results indicated subjects took food from the silent container when the competitor was not looking and chose randomly when the competitor was looking. This suggests rhesus macaques preferred to try to obtain food silently only when silence was relevant to obtaining the food surreptitiously. Similar results were obtained by Melis et al. (2006) with chimpanzees. However, Bräuer et al. (2008) did not find evidence that chimpanzees considered what a conspecific could hear. In this paradigm, pairs of chimpanzees competed over two pieces of food. What the dominant individual heard relative to the food baiting varied over trials. Results indicated that subordinates did not consider what the dominant competitor had heard with respect to food baiting even though they themselves could find the hidden food based on the noise created by food placement.

Interestingly, similar results were recently obtained with a nonmammalian species. More specifically, Stulp et al. (2009) found that Western scrub-jays (Aphelocoma californica) attempt to reduce the auditory information available to competitors when caching. In their study, jays were given caching opportunities for two different trays. One tray was filled with a substrate that made noise when birds cached in it; the second tray was filled with a substrate that did not make noise when birds cached in it. Birds were allowed to cache under several conditions: caching behaviour could be heard but not seen by conspecific competitors, caching behaviour could be neither seen nor heard by conspecific competitors, or caching behaviour could be seen and heard by conspecific competitors. The results indicated that birds only cached fewer food items in the noisy substrate under conditions in which they could be heard but not seen. These results suggest that scrub-jays, like rhesus macaques (Santos et al., 2006) and chimpanzees (Melis et al., 2006; but see Bräuer et al., 2008) consider how auditory information can change a competitor's knowledge state.

Given evidence indicating dogs' predilection to modify their behaviour to accord with humans' visual attention in situations in which they have been prohibited from taking food (e.g., Call et al., 2003; Schwab and Huber, 2006), we queried whether dogs might show a connection between hearing and knowing. Importantly, Bräuer et al. (2006) indicate that dogs can use sound as a cue to locate food even though they may not possess an understanding of the causal relationships involved in the noise production. Additionally, we explored whether performance varied depending on whether the dog lived in a private home or resided at an animal shelter, as recent evidence suggests dogs from shelters may perform more poorly in tests involving human social cues (e.g., Udell et al., 2008).

\section{Experiment}

\subsection{Animal, materials, and methods}

\subsubsection{Animals}

We tested 22 dogs living in private homes from the local area. Dogs living in private homes were at least 1 year of age, had been obtained from a breeder, lacked advanced obedience training, and were free of major health problems. They had resided with their owner for at least the last 6 months and were not fed within 3-4 h prior to participation. Staff instructed owners that there were no correct behaviours and reminded them they were not to help their dog in any way. Short commands such as stay, sit, and release by the owner were permitted.

In addition to dogs living in private homes, we also tested 24 dogs from a local animal shelter. The shelter dogs 
tested had been identified as strays (as opposed to surrenders or rescues) and were currently living in the local animal shelter in individual indoor runs. In selecting subjects, we used the following criteria: (1) was not on a staff hold (e.g., had undergone surgery within the previous $48 \mathrm{~h}$, was scheduled for surgery within the next $24 \mathrm{~h}$, had a major health issue such as seizures), (2) was not known to be aggressive, and (3) was over 6 months of age. Thus, we did not discriminate between breeds or readiness to approach the experimenters or accept food. All were tested within 1 week of arrival at the shelter.

\subsubsection{Materials}

One of several items was used as food reward, depending on the dog's preference. These included $1.25 \mathrm{~cm}$ beef hotdog segments, $1.25 \mathrm{~cm}$ bacon strips, or small commercial dog treats $(1.25 \mathrm{~cm}$ in diameter). Treats were placed on a white plastic plate $(25 \mathrm{~cm} \times 25 \mathrm{~cm})$ or hidden inside two translucent, clear plastic containers $(30 \mathrm{~cm} \times 15 \mathrm{~cm} \times 15 \mathrm{~cm})$. The front of each container was open to allow dogs access to the contents of the container. We hung 18 small brass bells $(1.25 \mathrm{~cm}$ in diameter) across each opening using thin plastic, translucent cord. The bells on each container were divided into strings of three and evenly spaced across the opening. The first container (noisy) had unaltered jingle bells that rang when either the container was moved or the contents of the container were manipulated (inserted or removed). The ringers within the second container's bells had been removed. As such, moving the container or manipulating the contents produced no ringing. Thus, the noisy and silent containers were visually identical to one another but differed in their propensity to make noise. The type of reward placed in the noisy and silent containers always matched.

\subsubsection{Methods}

The institution's Animal Care and Use Committee approved all procedures for all experiments. Testing occurred inside within a laboratory room of the institution $(6.0 \mathrm{~m} \times 7.6 \mathrm{~m})$ for dogs residing in private residences and in a large grass field behind the animal shelter for shelter dogs.

In all cases, dogs were allowed to familiarize themselves with their surroundings by exploring the area (10-15 min). Following acclimation, dogs first completed a short inhibition task to mark the human as a "gatekeeper" for treats. As the dog watched, a food reward was placed on a plate. The dog was commanded via a familiar command ("No", "Wait", etc.) not to consume the treat. For dogs residing in private homes, the command was determined by asking the owner for a familiar command they typically used to instruct their dog not to take a food item. For dogs residing in the animal shelter, "No" was used. Following the command, the experimenter and owner (for dogs in private homes) remained still and silent. A digital stopwatch was used to determine the latency for the dog to take the treat. Dogs were allowed a maximum of $5 \mathrm{~min}$ to take the treat. If the dog had not taken the treat within $5 \mathrm{~min}$, the dog was given the treat.

Following the inhibition task, dogs encountered one experimental trial (Looking or Not Looking, as described below). These trials were videotaped (Everio GZ-MG630,
JVC, Wayne, NJ, USA) in real time. Dogs sat or stood. Both the noisy and silent containers were placed in front of them. The containers were located at least $1.5 \mathrm{~m}$ from the dog and at least $1 \mathrm{~m}$ apart. The containers were always centered with respect to the dog's position; the identity of the container on the right and left was counterbalanced across subjects. The owner (dogs in private residences) or a handler (dogs in the animal shelter) kept a firm hand on the dog's leash until it was time for it to respond. The owner/handler stood behind their dog.

The experimenter stood between the two containers. After gaining the dog's attention, she moved to each container and placed a treat inside according to a predetermined order, which was counterbalanced across subjects. During placement, the experimenter demonstrated the auditory properties of the container by moving the treat up and down against the middle string of bells five times. Care was taken to manipulate the treat against the bells for an equivalent amount of time in an equivalent position and fashion for both containers. This action caused the bells on the noisy container to ring while the same action resulted in no ringing for the silent container. Following treat placement, the experimenter adopted one of two positions: "Looking" or "Not Looking”. Which position was adopted was determined randomly. In the Looking position, the experimenter sat between the two containers and faced straight ahead. In the Not Looking position, the experimenter pulled her knees to her chest and placed her head between her knees facing the ground. Dogs were then released and allowed $30 \mathrm{~s}$ to approach one container. All dogs approached within the allotted time. The dog was allowed to retrieve and eat only the food reward from the container it approached. Approach was defined as the dog's touching the food reward container with its snout or appendage. The identity of this container was recorded.

\subsubsection{Statistical analyses}

Coding of the experimental trials (Looking and Not Looking) was performed by two naïve coders through digital video recordings. The coders evaluated the dogs' choices with the sound muted. As the actions executed by the experimenter were equivalent with respect to the two containers and the containers were visually identical, the coders were blind to trial type during coding. Initial agreement across the coders was high for both dogs residing in private residences (94\%) and shelter dogs (100\%). When coders did not initially agree in their observations for dogs residing in private residences, coders came to consensus after being reminded of the approach criterion. Results from statistical analyses (binomial and chi-square test for independence) were only considered significant if $P<0.05$. All statistical tests were two-tailed. The SPSS statistical package (Version 16.0, SPSS, Chicago, IL, USA) was used for all statistical tests. Although the dogs' latency to take the treat in the inhibition task was recorded, it is not reported here as it is not directly relevant to the question under investigation. It merely established the human experimenter as a gatekeeper to treats. 


\section{Results}

Twenty dogs living in private residences successfully completed the experimental trial, 10 in each condition (Looking: five males, $M=3.2$ years, $s d=0.4$; Not Looking: six males, $M=3.1$ years, $s d=0.5$ ). Two additional dogs were excluded. One dog's owner pointed to the silent container while another failed to acclimate to his surroundings prior to the inhibition task. These data were not included in any analyses.

Four subjects approached the silent container in the Looking condition (binomial test: $P=0.8$ ) while 10 approached the silent container in the Not Looking condition (binomial test: $P=0.004$ ). As subjects were randomly assigned to either the Looking or Not Looking condition, we compared dogs' pattern of performance between conditions using a chi-square test for independence. This test indicated that subjects significantly preferred the silent container only in the Not Looking condition $\left(\chi_{1}^{2}=8.8\right.$, $P=0.003$ ).

Twenty shelter dogs successfully completed the experimental trial, 10 in each condition (Looking: four males, $M=3.4$ years, $s d=0.8$; Not Looking: six males, $M=3.6$ years, $s d=0.6$ ). Four additional dogs were excluded. One was excluded due to excessive activity, one for food aggressiveness, one for interference from a squirrel, and one due to experimenter error. These data were not included in any analyses.

Four subjects approached the silent container in the Looking condition (binomial test: $P=0.8$ ) while nine approached the silent container in the Not Looking condition (binomial test: $P=0.02$ ). As subjects were randomly assigned to either the Looking or Not Looking condition, we compared dogs' pattern of performance between conditions using a chi-square test for independence. This test indicated that subjects significantly preferred the silent container only in the Not Looking condition $\left(\chi_{1}^{2}=5.5\right.$, $P=0.02$ ).

\section{Discussion}

The results indicate that when given a choice between a noisy container and a silent container from which to take a treat, dogs living in private residences and dogs living in the animal shelter, significantly preferred the silent container only when the experimenter, a human gatekeeper, was not looking. As such, dogs in this condition consistently picked the container that did not alert the human experimenter to the fact that the food reward was being removed from the container while she was not looking. When the human gatekeeper was looking, dogs showed no reliable pattern of approach. This suggests that dogs' pattern of approach in the Not Looking condition was not due to either a general preference for the silent container or an aversion to the noisy container. Instead, dogs appeared to prefer the silent container only when the experimenter was not looking and therefore did not have knowledge of their approach. This suggests dogs took into account the noise caused by their approach only when that noise could change what the experimenter knew about their actions.
Overall, the results suggest dogs consider how auditory information can change what a human knows. This result accords with previous results from studies with rhesus macaques (e.g., Santos et al., 2006) and chimpanzees (Melis et al., 2006) suggesting that they can take into account what a human competitor can and cannot hear, as well as results from Stulp et al. (2009) suggesting Western scrub-jays attempt to reduce the auditory information available to potential cache pilferers. Additionally, this result is consistent with results from chimpanzees, rhesus macaques, and goats in the visual domain (e.g., Flombaum and Santos, 2005; Kaminski et al., 2005; Bräuer et al., 2007; Hare et al., 2006). These data add to the continuing debate concerning what have been purported as "mind-reading" tasks in nonhuman animals. Many researchers interpret nonhuman primates' adept performance in such competition tasks as evidence for some form of theory of mind abilities (e.g., Tomasello et al., 2003; Flombaum and Santos, 2005), the ability to attribute mental states to oneself and others and understand that others have beliefs, desires, and intentions that may differ from one's own. However, other researchers have adopted alternative explanations of successful performance such as behaviour reading (e.g., Povinelli, 2004; Povinelli and Vonk, 2004). According to the latter view, subjects perform well in competition tasks because they are skilled at calculating the probability that their actions will lead to specific future competitor behaviours. For instance, a subordinate chimpanzee might recognize that approaching a dominant individual that is looking at him/her is more likely to lead to future retaliation than approaching a dominant individual without this visual link. Importantly, this would not require the chimpanzee to possess any knowledge of the competitor's mental state.

However, our results, like those of Santos et al. (2006) pose problems for such behaviour-reading explanations. This is because such accounts rely on subjects' association between an overt feature of the competitor (e.g., eye gaze) and her/his future actions (e.g., approach or retaliation). This task, however, lacks that link as dogs rarely (if ever) encounter jingle bells in their environment. Dogs in our experiments also lacked experience with how a human would behave towards them when they are looking/not looking and a jingle bell is heard/not heard. Thus, it is unlikely that dogs could have formed the historical link required for a behaviour-reading account to remain a feasible explanation of their behaviour. A behaviour-reading account would almost certainly need to incorporate generalization between past associations a subject might have learned in similar situations and the current experimental situation in order to account for dogs' behaviour. According to current behaviour-reading theories (e.g., Povinelli, 2004; Povinelli and Vonk, 2004), it is not clear if or under what circumstances such generalization might occur. Instead, our data suggest dogs succeeded by utilizing representations about what others perceive (heard or did not hear).

Interestingly, our results conflict with recent data suggesting that shelter dogs may perform more poorly than pet dogs in tasks requiring reading of human social cues 
(e.g., Udell et al., 2008). For example, Udell et al. recently found that shelter dogs failed to follow a momentary distal point cue (i.e., the experimenter briefly exhibited a traditional pointing gesture in the direction of the baited container) to find food while pet dogs tested indoors and wolves (Canis lupus) did. In a subsequent study, Udell et al. (2010) found that shelter dogs were able to learn to follow a momentary distal point after further training. However, in our experiment, a dog's life history did not appear to affect the dog's propensity to take into account what a human gatekeeper could and could not hear. Why did shelter dogs initially succeed in this social task and not in others (e.g., Udell et al., 2008)? Perhaps one explanation is that the situation of retrieving and consuming food without being noticed by humans is a familiar situation to many stray animals, including dogs. Although shelter dogs had likely not encountered jingle bells before, the experimental procedure likely took advantage of a familiar competitive situation for these animals. Importantly, the success of shelter dogs in our paradigm does not imply that they would necessarily succeed in other paradigms involving human social cues. However, it might be the case that competition/gatekeeper scenarios provide a more sensitive measure of whether shelter dogs' can attend to a variety of human social cues.

Future research might more fully characterize the nature of such representations through investigating the circumstances under and individuals (i.e., humans versus conspecifics) with which such behaviour arise, whether differences emerge in conditions where dogs produce noise versus play a more passive role, as well as determine if and when dogs intentionally engage in behaviour to change the perceptions of others.

\section{Conclusion}

Our findings suggest shelter dogs, similar to pet dogs, show sensitivity to human social cuing when a human serves as a gatekeeper. This implies that perhaps shelter dogs may be more likely to evidence sensitivity to some forms of human social cues under competitive/gatekeeper circumstances than situations in which a human is cooperative. As a result, these findings have implications for future research seeking to understand whether other circumstances exist in which shelter dogs exhibit similar sensitivities to social cues as humans. If additional circumstances are identified, this research may contribute to better understanding the mechanisms underlying dogs' knowledge of social cues emitted by humans. Further, the finding that dogs, in general, recognized that hearing an auditory signal can change a human's knowledge state may have important applied implications for understanding and using dogs' abilities in working contexts that demand dogs' discriminating the circumstances in which humans can perceive their actions. Indeed, if dogs understand when humans are not sensitive to their actions, perhaps this is an ability that can be reliably trained in dogs for use in law enforcement or military contexts. Such abilities might provide an additional avenue for both shelter and non-shelter dogs to assist humans.

\section{Acknowledgements}

We would like to thank the animal shelter, dogs, and dog owners that participated. We thank Jessica Arbuthnot, Ayelet Baruch, and Ariel Coshun for their aid in data collection and coding.

\section{References}

Agnetta, B., Hare, B., Tomasello, M., 2000. Cues to food locations that domestic dogs (Canis familiaris) of different ages do and do not use. Anim. Cogn. 3, 107-112.

Bräuer, J., Call, J., Tomasello, M., 2007. Chimpanzees really know what others can see in a competitive situation. Anim. Cogn. 10, 439-448.

Bräuer, J., Call, J., Tomasello, M., 2008. Chimpanzees do not take into account what others can hear in a competitive situation. Anim. Cogn. $11,175-178$.

Bräuer, J., Kaminski, J., Riedel, J., Call, J., Tomasello, M., 2006. Making inferences about the location of hidden food: social dog, causal ape. J. Comp. Psychol. 120, 38-47.

Bugnyar, T., Heinrich, B., 2006. Pilfering ravens, Corvus corax, adjust their behaviour to social context and identity of competitors. Anim. Cogn. 9, 369-376.

Bugnyar, T., Kotrschal, K., 2004. Leading a conspecific away from food in ravens (Corvus corax). Anim. Cogn. 7, 69-76.

Call, J., Bräuer, J., Kaminski, J., Tomasello, M., 2003. Domestic dogs (Canis familiaris) are sensitive to the attentional state of humans. J. Comp. Psychol. 117, 257-263.

Clutton-Brock, J., 1999. A Natural History of Domesticated Mammals. Cambridge University Press, Cambridge.

Flombaum, J.I., Santos, L.R., 2005. Rhesus monkeys attribute perceptions to others. Curr. Biol. 15, 447-452.

Hare, B., Call, J., Tomasello, M., 2006. Chimpanzees deceive a human competitor by hiding. Cognition 101, 495-514.

Hare, B., Addessi, E., Call, J., Tomasello, M., Visalberghi, E., 2003. Do capuchin monkeys, Cebus apella, know what conspecifies do and do not see? Anim. Behav. 65, 131-142.

Hare, B., Tomasello, M., 2005. Human-like social skills in dogs? Trends Cogn. Sci. 9, 439-444.

Horowitz, A., 2009. Attention to attention in domestic dog (Canis familiaris) dyadic play. Anim. Cogn. 12, 107-118.

Kaminski, J., Riedel, J., Call, J., Tomasello, M., 2005. Domestic goats, Capra hircus, follow gaze direction and use social cues in an object choice task. Anim. Behav. 69, 11-18.

Karin-d'Arcy, M., Povinelli, D., 2002. Do chimpanzees know what each other see? A closer look. Int. J. Comp. Psychol. 15, 21-54.

Lakatos, G., Soproni, K., Dóka, A., Miklósi, Á., 2009. A comparative approach to dogs' (Canis familiaris) and human infants' comprehension of various forms of pointing gestures. Anim. Cogn. 12, 621-631.

Melis, A.P., Call, J., Tomasello, M., 2006. Chimpanzees (Pan troglodytes) conceal visual and auditory information from others. J. Comp. Psychol. 120, 154-162.

Povinelli, D.J., 2004. Behind the ape's appearance: escaping anthropomorphism in the study of other minds. Daedalus (Winter), 29-41.

Povinelli, D.J., Vonk, J., 2004. We don't need a microscope to explore the chimpanzee mind. Mind Lang. 19, 1-28.

Santos, L., Nissen, A., Ferrugia, J., 2006. Rhesus monkeys, Macaca mulatta, know what others can and cannot hear. Anim. Behav. 71, 1175-1181.

Schloegl, C., Kotrschal, K., Bugnyar, T., 2008. Do common ravens (Corvus corax) rely on human or conspecific gaze cues to detect hidden food? Anim Cogn. 11, 231-241.

Schwab, C., Huber, L., 2006. Obey or Not Obey? Dogs (Canis familiaris) behave differently in response to attentional states of their owners. J. Comp. Psychol. 120, 169-175.

Stulp, G., Emergy, N.J., Verhulst, S., Clayton, N.S., 2009. Western scrub-jays conceal auditory information when competitors can hear but cannot see. Biol. Lett. 23, 583-585.

Tomasello, M., Call, J., Hare, B., 2003. Chimpanzees understand psychological states-the question is which ones and to what extent. Trends Cogn. Sci. 7, 153-156 
Udell, M., Giglio, R., Wynne, C., 2008. Domestic dogs (Canis familiaris) use human gestures but not nonhuman tokens to find hidden food. J. Comp. Psychol. 122, 84-93.

Udell, M., Dorey, N., Wynn, C., 2010. The performance of stray dogs (Canis familiaris) living in a shelter on human-guided object-choice tasks. Anim. Behav. 79, 717-725.
Vilà, C., Savolainen, P., Maldonado, J.E., Amorim, I.R., Rice, J.E., Honeycutt, R.L., Crandall, K.A., Lundeberg, J., Wayne, R.K., 1997. Multiple and ancient origins of the domestic dog. Science 276, 1687-1689. 